\title{
Impact of Vocabulary Learning Tasks on Communicative Gains of Advanced EFL Learners of Persian
}

\author{
Fariba Rahimi Esfahani \\ English Department, Islamic Azad University-Shahrekord Branch,Shahrekord, Iran \\ Rahimi_fariba@yahoo.com
}

\begin{abstract}
The extent to which receptive and productive vocabulary learning tasks affect the development of L2 lexical knowledge and the conditions which can help the learners to acquire L2 words through appropriate classroom instructions have been matters of great concern to the practitioners in L2 vocabulary research.. This paper investigated the effects of receptive and productive learning from word pairs on comprehension, and the use of taught words in writing in advanced EFL learners of Persian. To this end, a quick Oxford Placement Test (OPT) was administered to the senior students population studying English teaching in Shahrekord Azad university, and based on their OPT scores, a samples of 40 male and female students was selected and randomly assigned to two equal groups of 20 each. One group was taught 15 target words receptively while another group learned the same target words productively. After the treatments, two tests measuring reading comprehension and writing were administered to each group. The scores of the groups were analyzed via a one-way MANOVA. The results indicated that those who had learned their target words productively outperformed the receptive participants on the writing test significantly. Similarly, the receptive group did significantly better on the reading comprehension test than the productive group. The findings of this study revealed that receptive vocabulary learning may be more beneficial to understanding a text and productive learning is more effective in improving the use of students' taught words in writing. The results of this study can benefit teachers and students to become aware of the merits and demerits of vocabulary learning tasks, and help them to select the tasks that best suit their needs.
\end{abstract}

Keywords Receptive Learning, Productive Learning, Comprehension, Writing, EFL (English As A Foreign Language)

\section{Introduction}

\section{a .L2 Vocabulary Knowledge}

Although vocabulary is regarded as an essential element in L2 learning, less attention has been paid to the theoretical establishment of vocabulary learning than that of L2 grammar learning. However, there has recently been a noticeable increase in L2 research into vocabulary learning. The L2 vocabulary research has mainly dealt with the issues like 'what it means to know a word' and 'how words are learned and how they are used'. That is, L2 vocabulary research has been devoted to the identification of lexical knowledge and the memorization, storage, and retrieval of lexical knowledge[1]. Henriksen[2] suggests that the construct of lexical competence should consist of three dimensions: a "partial-precise knowledge" dimension in which levels of knowledge equal to different levels of word comprehension, a "depth of knowledge" dimension which also covers knowledge components identified in the vocabulary depth

* Corresponding author:

Rahimi_fariba@yahoo.com(Fariba Rahimi Esfahani)

Published online at http://journal.sapub.org/economics

Copyright (C) 2012 Scientific \& Academic Publishing. All Rights Reserved dimension[3- 4] and a "receptive-productive" dimension which concerns how well a learner can access and use a word. The receptive and productive dimension of lexical knowledge is "a bridging dimension between lexical competence and performance" [5].

Therefore, With regard to the acquisition of L2 vocabulary knowledge and its use, on the other hand, we also need to distinguish between receptive (passive) and productive (active) vocabulary knowledge, since these types of lexical knowledge - receptive vs. productive - require different amounts of learning time, different effects on vocabulary acquisition, and different learning methods[6-7-8-9-10].

\section{b. Receptive vs. Productive Vocabulary Knowledge}

Up to now, many scholars have made definitions from different perspectives for receptive and productive vocabulary knowledge. "Receptive knowledge" is defined as "being able to understand a word"[11]; and it includes words which can be understood or recognized as individuals can assign their meanings while listening or reading (sometimes imperfectly) and which are also less well-known and less frequent in use and not used spontaneously[12]; it is the ability to perceive the form of the word and to retrieve its mean$\operatorname{ing}(\mathrm{s})[13]$; it is the knowledge of the meaning of an L2 word; prototypically, being able to translate a word from L2 to L1[9]; and it refers to the ability of the learners to understand 
a word's meaning[Read; 2000 cited in 14]. In regard to productive vocabulary knowledge, it includes the production of a word of "one's own accord"[11]; it refers to words that can be written or spoken frequently without hesitation as they are well-known and familiar[12]; it requires retrieving the appropriate spoken or written word form of the meaning to be expressed[13]; and it also includes being able to express a concept by means of an L2 word; prototypically, being able to translate a word from L1 to L2 [9].

c. The Effect of vocabulary knowledge on comprehension

Success in reading comprehension is usually seen as fundamental to the academic success of foreign language learners. Second language proficiency often assumes vocabulary and grammar as knowledge and reading as the ability to understand the text[15]. Research consistently reveals that vocabulary knowledge heavily relates to reading comprehension more so than other factors such as grammar knowledge[3-15]. While there have been many Ll studies investigating the effects of vocabulary instruction on comprehension, there have been very few L2 studies. Johnson[16] found that studying the definitions of target words prior to reading a passage had no significant effects on two comprehension tests. However, very little detail was given about the instruction including how much time was spent on the task.

\section{Hypotheses}

To investigate the impact of lexical learning tasks (productive vs. receptive) on communicative knowledge of advanced EFL learners of Persian, the following hypotheses were formulated:

1. Receptive learning of vocabulary from word pairs leads to more successful comprehension of the vocabulary in reading than productive learning in advanced EFL learners of Persian.

2. Productive learning of vocabulary from word pairs leads to more successful use of the vocabulary in writing than receptive learning in advanced EFL learners of Persian.

\section{Methodology}

\section{a. Participants}

The participants in this experiment were 40 advanced Iranian EFL learners (both male and female) in Azad University of Shahrekord, Iran. They were chosen from 100 applicants through a quick Oxford Placement Test ( OPT) based on their scores which ranged from 48 to 60 . The subjects were randomly assigned to two experimental groups.

\section{b. Material}

A quick OPT was used in this study to determine the level of proficiency of potential subjects. 15 target words (9 nouns and 6 verbs) were chosen from Nation's BNC list at 10 th level of frequency. Nine nouns and six verbs were se- lected as target words because nouns and verbs are the most common parts of speech found in natural text, and the 9:6 ratios approximates their proportional frequency of occurrence in language use[18]. The number of target words was determined during pilot studies. These target words were replaced with disguised forms to ensure that the subjects had no prior knowledge of the target words. All of the disguised forms were two syllables, and resembled English words phonetically and orthographically. The disguised forms and their English meanings were as follows: napid (bubble), zotel (hairdryer), tamel (bookshelf), folid ( yarn), todest (sunflower), labit (subway), heper (bangle), raggle (dormitory), jartner ( aquarium), melect (glisten), tansel (hunch), nasin (brandish), toncop (dabble), cader (chuckle), ho$\operatorname{det}($ clasp).

Moreover, 2 tests were used to measure the effects of receptive and productive learning tasks on writing and comprehension. The first test that was administered after the treatments was a picture description test. It was used to measure the subjects' use of the target words in writing. The comprehension test followed the picture description test. The comprehension test used a true/false format

\section{Design and Procedure}

Two experimental groups were used in this study to examine the effects of receptive and productive learning on writing and reading in advanced EFL learners of Persian. One experimental group studied 15 L2 target words receptively, and the other group studied the same target words productively. In the receptive treatment, the target words were presented in a column on the left side of a paper, and their translations were presented on their right. The subjects were instructed to cover the translations and then look at the target words and try to recall their translations. If they could not recall a meaning, the subjects were told to uncover the translation and check the meaning. In the productive treatment, the translations were on the left and the target words were on the right. The subjects completed the same task except they covered the target words, and then tried to recall them. Each group was given 10 minutes to complete their task. Two tests measuring writing and comprehension were administered immediately after the treatments. The writing test was given first followed by the comprehension test.

The results of the groups were compared to determine how receptive and productive learning from word pairs contributed to writing and comprehension in advanced Iranian EFL learners

\section{Results}

The descriptive statistics (means, standard deviations, and number of subjects) of the scores for the picture description test and reading comprehension test are reported in Table 1. To determine whether there were any overall differences 
among the treatment groups, a multivariate analysis of variance (MANOVA) was performed using the scores on the two dependent measures (picture description test and reading comprehension test). The independent variable was the type of learning task (receptive and productive learning of vocabulary). The MANOVA revealed an overall significant multivariate main effect for the task, Wilks' lambda is .325 , $\mathrm{F}(2,37)=38.450, \mathrm{P}<.05$.Thus, it can be concluded that task had a significant effect on the dependent variables (The results are shown in table 2).

Table1. Descriptive Statistics

\begin{tabular}{|cc|c|c|c|}
\hline & TASK & Mean & $\begin{array}{c}\text { Std. De- } \\
\text { viation }\end{array}$ & $\mathrm{N}$ \\
\hline $\begin{array}{c}\text { pic_descript } \\
\text { ion }\end{array}$ & RECEPTIVE & 9.2000 & 1.32188 & 20 \\
& PRODUCTIVE & 10.1500 & 1.34849 & 20 \\
& Total & 9.6750 & 1.40306 & 40 \\
comprehen- & RECEPTIVE & 12.3000 & 1.30182 & 20 \\
& PRODUCTIVE & 8.6500 & 1.42441 & 20 \\
& Total & 10.4750 & 2.28695 & 40 \\
\hline
\end{tabular}

Table 2. Multivariate Tests (b)

\begin{tabular}{|c|c|c|c|c|c|c|}
\hline \multicolumn{2}{|l|}{ Effect } & Value & $\mathrm{F}$ & $\begin{array}{c}\text { Hy- } \\
\text { pothesis } \\
\text { df }\end{array}$ & $\begin{array}{c}\text { Error } \\
\text { df }\end{array}$ & Sig. \\
\hline \multirow[t]{4}{*}{$\begin{array}{c}\text { TAS } \\
\mathrm{K}\end{array}$} & Pillai's & .675 & 38.450 & 2.000 & 37.000 & .000 \\
\hline & $\begin{array}{l}\text { Wilks' } \\
\text { Lambda }\end{array}$ & .325 & $\begin{array}{l}38.450 \\
\text { (a) }\end{array}$ & 2.000 & 37.000 & .000 \\
\hline & $\begin{array}{l}\text { Hotelling's } \\
\text { Trace }\end{array}$ & 2.078 & $\begin{array}{l}38.450 \\
\text { (a) }\end{array}$ & 2.000 & 37.000 & .000 \\
\hline & $\begin{array}{c}\text { Roy's } \\
\text { Largest } \\
\text { Root }\end{array}$ & 2.078 & $\begin{array}{l}38.450 \\
\text { (a) }\end{array}$ & 2.000 & 37.000 & .000 \\
\hline
\end{tabular}

\section{a Exact statistic}

Given the significance of the overall test, the univariate main effects were examined. Table 1 shows that the subjects that learned the target words in the productive task outperformed those that completed the receptive task on the picture description test. Table 3 shows that the productive group significantly outperformed the receptive group on the picture description test $(\mathrm{F}(1,37)=5.062, \mathrm{p}<.05)$.Moreover, the receptive group demonstrated larger gains on the reading comprehension test $(\mathrm{F}(1,37)=71.555, \mathrm{p}<.05)$. A summary of the statistical analysis is shown in table 3 .

Table 3. Tests of Between-Subjects Effects

\begin{tabular}{|cc|c|c|c|c|c|}
\hline Source & $\begin{array}{c}\text { Dependent } \\
\text { Variable }\end{array}$ & $\begin{array}{c}\text { Type III } \\
\text { Sum of } \\
\text { Squares }\end{array}$ & df & $\begin{array}{c}\text { Mean } \\
\text { Square }\end{array}$ & F & Sig. \\
\hline TASK & $\begin{array}{c}\text { pic_descrip } \\
\text { tion } \\
\text { compre- } \\
\text { hension }\end{array}$ & 9.025 & 1 & 9.025 & 5.062 & .030 \\
\hline
\end{tabular}

Following the results, task did have a significant effect on the dependent variables. As table 1 shows, the receptive group significantly outperformed the productive group on the reading comprehension test. Thus, Hypothesis 1 is supported. That is, receptive learning of vocabulary from word pairs led to more successful comprehension of the vocabulary in reading than productive learning in advanced EFL learners of Persian. Moreover, the productive group outperformed the receptive group on the picture description test and their scores were significantly higher. Therefore, Hypothesis 2 is also confirmed. That is, Productive learning of vocabulary from word pairs led to more successful use of the vocabulary in writing than receptive learning in advanced EFL learners of Persian.

\section{Discussion}

This research investigated the relative effectiveness of receptive and productive learning from word pairs on comprehension and writing. A comparison of the two tasks indicated that receptive learning contributed to significantly higher scores on the comprehension test than productive learning. Moreover, the productive groups did significantly better on the picture description test.

The results of the picture description and comprehension tests suggest that receptive vocabulary learning may be more beneficial to understanding a text and productive tasks may have greater effect on writing. This is supported by earlier findings that have shown that receptive learning from word pairs is better suited to developing receptive vocabulary knowledge[6-9-10-17]. Therefore, if the primary aim of instruction is to improve comprehension, receptive tasks may be more effective.

Since previous research has indicated that productive tasks may be effective[19], and that productive learning might be better suited to developing productive vocabulary knowledge than receptive learning[6-10-17], it should not be surprising that productive learning from word pairs was superior on the picture description test. Writing is essentially a productive task that involves several different types of productive vocabulary knowledge. To write a sentence, learners must produce the forms of the words, and then use them with syntactic, semantic, and grammatical accuracy. Since receptive learning tends to focus learners on understanding language rather than producing it, it would be puzzling if receptive tasks were more effective than productive tasks in improving writing.

Taken as a whole, the results of the picture description and comprehension tests suggest that L2 vocabulary learning may improve comprehension and writing with performance dependent on the method of instruction. Receptive learning from word pairs was found to be a more effective method of increasing comprehension than productive learning from word pairs. In turn, this suggests that receptive learning may be better suited to improving comprehension than productive learning. Productive learning from word pairs was found to be better suited to improving writing than receptive learning 
from word pairs. This suggests that productive tasks may be more effective if the aim is to use taught words.

In regard to instructional practice, the results of this study help teachers and students know that which tasks are more useful for acquiring which aspect of communication. It will also show what each task contribute to vocabulary knowledge as well as which tasks may complement each other to improve learning. Those involved in vocabulary learning should be aware that the tasks that are used might have a powerful effect on what learners can and cannot do with a word. Since the majority of tasks used in vocabulary learning are receptive, they are well suited for improving receptive knowledge or comprehension but less appropriate for improving the use of taught words productively. Common teaching methods such as providing a definition or translation, and looking up words in the dictionary may be more conducive to increasing receptive knowledge. However, if the aim of a learner or an instructional program is to improve speaking and writing, teachers and learners need to be aware that they may be more successful if they use productive tasks. If their goal is to improve overall language skills, the results indicate that a combination of receptive and productive tasks may prove to be most effective.

\section{REFERENCES}

[1] Carter, R. (2001). Vocabulary. In The Cambridge Guide to Teaching English to Speakers of Other Languages, edited by Carter, R. \& Nunan, D., pp. 42- 47. Cambridge: CUP.

[2] Henriksen, B. (1999). Three Dimensions of Vocabulary Development. Studies in Second Language Acquisition, 21, pp 303-317567-595.

[3] Qian, D. D. (1999). Assessing the roles of depth and breadth of vocabulary knowledge in reading comprehension. Canadian Modern Language Review,56, 282-307.

[4] Qian, D. D. \& Schedl, M. (2004). Evaluation of an in-depth vocabulary Knowledge measure for assessing reading performance. Language Testing, 21, 28-52.

[5] Zareva, A., Schwanenflugel, P., Nikolova, Y. (2005) Relationship Between Lexical Competence And Language Proficiency. Studies in Second Language Acquisition, 27, 567-595.

[6] Waring, R. (1997c). A comparison of the receptive and productive vocabulary sizes of some second language learners.
Immaculata Notre Dame Seishin University, Okayama 1: 53-68.

[7] Laufer, B., and Paribakht, T.S. (1998). The relationship between passive and active vocabularies: effects of language learning context. Language Learning 48, 3: 365-39t.

[8] Nation, I.S.P. (2001). Learning vocabulary in another language. Cambridge University Press, Cambridge.

[9] Mondria, J., \& Wiersma, B. (2004). Receptive, productive, and receptive + productive L2 vocabulary learning: What difference Does It Make?, In Vocabulary in a second language. Amsterdam: John Benjamins.

[10] Webb, S. (2005). Receptive and productive vocabulary learning: The effects of reading and writing on word knowledge. Studies in Second Language Acquisition, 27, 33-52.

[11] Schmitt, N. (2000). Vocabulary in language teaching Cambridge University Press, Cambridge.

[12] Kamil, M., Hiebert, E. H. (2005). Teaching and Learning Vocabulary: Perspectives and Persistent Issues. In P, Kamil, M. \& Hiebert, E. H. (Eds.), Teaching and Learning Vocabulary Bringing Research to Practice (1-23). New Jersey, USA: Lawrence Erlbaum Associates, Publishers.

[13] Laufer, B., \& Goldstein, S. (2004). Testing vocabulary knowledge: Size, strength, and computer adaptiveness. Language Learning, 54, 399-436.

[14] Uygun,A.A.(2009). The Effects of Receptive and Productive Tasks on Vocabulary Retention. Master Thesis, Anadolu University, Institute of Educational Sciences.

[15] Koda, K. (2005). Insights into second language reading: A cross-linguistic approach. Cambridge, UK: Cambridge University Press.

[16] Johnson, P. (1982) Effects on reading comprehension of building background knowledge. TESOL Ouarterly 16, 4: 503-516.

[17] Griffin, G.F. and Harley, T.A. (1996). List learning of second language vocabulary. Applied Psycholinguistics 17 : 443-460.

[18] Kucera, H. and Francis, W.N. (1967) A computational analysis of present-day American English Brown University Press, Providence, R.I.

[19] Duin, A.H. and Graves, M.F. (1987). Intensive vocabulary instruction as a prewriting technique. Reading Research Ouarterly $22,3: 311-330$. 